\title{
Contradicciones y desafíos en el capitalismo del siglo XXI. La segunda crisis de larga duración
}

\author{
Andrés PIQUERAS INFANTE \\ Universitat Jaume I de Castelló \\ piqueraa@fis.uji.es
}

Recibido: 28-01-2014

Aceptado: 13-10-2014

\begin{abstract}
Resumen:
El capitalismo histórico ha padecido dos Grandes Crisis de Larga Duración, que se separan entre sí por un siglo de distancia y que han dado lugar a dos Grandes Mutaciones capitalistas. La primera Gran Crisis comenzó en los años 70 del siglo XIX y tras las mayores convulsiones que hasta entonces había experimentado el capitalismo (crack bursátil, Guerras Mundiales, revoluciones...), finalizó en sus formaciones centrales en un capitalismo "diferente”, una mutación o híbrido cuya dinámica de reproducción tuvo que ser asistida permanentemente por el Estado a través del Departamento III o de servicios sociales (asentando el modelo de acumulación-regulación llamado "keynesiano”).

La Segunda Crisis de Larga Duración comenzó hacia 1973 y del intento de escapar de ella resultó una mutación de sentido contrario, que implicó una permanente asistencia del Estado de cara a deprimir la demanda, concentrar la riqueza social y mantener en parte el consumo a través de la financiarización de la economía (crédito-endeudamiento y especulación o "keynesianismo del precio de activos").

La tesis que se defiende aquí es que estamos en el límite de las posibilidades del (intento de) modelo de crecimiento neoliberal-financiarizado que surgió de ello, e instalados en una fase de alta inestabilidad sistémica, incertidumbre y convulsiones. A partir de esto el artículo analiza las numerosas contradicciones y desafíos a los que se enfrenta hoy el capitalismo, que bien pueden marcar el inicio de otra Gran Mutación del mismo de cara a un ignoto modelo de acumulación-regulación. Sin embargo, también pueden ser evidencia de su declive (un largo declive que inició al agotar las posibilidades del modelo que lo salvó en el pasado: el keynesianismo).
\end{abstract}

Palabras clave: crisis; mutaciones; financiarización; acumulación; regulación; contradicciones.

\section{Contradictions and Challenges in the Twenty-First Century Capitalism. The Second Long-Last Crises}

\begin{abstract}
:
The history of capitalism has seen Two Great Long-Lasting Crises separated by one century and which have been marked by two Great Capitalist Mutations. The first Great Crisis started in the early 1870s and after a series of big upsets suffered by capitalism (stock market crash, two World Wars, revolutions...), a new form of "different" capitalism emerged within its central core in the form of a mutation or hybrid whose reproductive mode had to be permanently propped up by the State through Department III or social services (under the so-called "Keynesian” accumulation-regulation model).

The Second Great Long-Lasting Crisis started around 1973 and the attempt made to escape it resulted in a mutation in reverse, marked by the State's permanent attempt at reducing demand, concentrating wealth and partially maintaining consumption through the financialisation of the economy (the
\end{abstract}


combination of credit-growing debt set amidst speculation or the "Keynesian treatment of the price of assets”).

The argument that is put forward here is that we are at the sheer limits of the possibilities offered by a neoliberal-financialised (attempt of) growth model that came into being through the second mutation. This situation is reflected by high systemic instability, uncertainty and violent readjustments. This article analyses the many contradictions and challenges that are faced by today's capitalism; it is suggested that in consequence a further Great Mutation may take place based on a still unclear model of accumulation-regulation. However it can also provide evidence for capitalist decline (a long process of decline that commenced with the limits of the model that saved it in the past: Keynesian political economy).

Keywords: crisis; mutations; financialisation; accumulation; regulation; contradictions.

\section{Referencia normalizada}

Piqueras Infante, A. (2014): “Contradicciones y desafíos en el capitalismo del siglo XXI. La segunda crisis de larga duración”, Política y Sociedad, 51(3), pp. 695-725.

Sumario: Introducción. Un sistema que alberga su crisis. Las Crisis de Larga Duración o Grandes Crisis sistémicas. 1. La Larga Crisis del fin del siglo XX y principios del XXI. 2. El neoliberalismo financiarizado. ¿Nuevo modelo de crecimiento? 3. Contradicciones y desafíos ineludibles. Bibliografía.

\section{Introducción. Un sistema que alberga su crisis. Las Crisis de Larga Duración o Grandes Crisis sistémicas}

En el sistema capitalista la tendencia a la crisis económica se debe a la caída de la masa de ganancia aun manteniéndose la productividad, debido a un proceso de sobreacumulación de capital.

Esta tesis clásica del materialismo histórico se explica de la siguiente manera. Por un lado, la automatización o, en general, la tendencia al desarrollo de las fuerzas productivas, que se supone inherente a la acumulación capitalista, tiende a la mayor utilización de (e innovación en) tecnologías intensivas en capital. Estas últimas entrañan una significativa menor utilización de fuerza de trabajo por unidad de capital invertido, lo que además de provocar una tendencia hacia la eliminación de empleos implica una consecuencia realmente grave para el funcionamiento capitalista, que es la sobreacumulación de capital invertido por unidad de valor que se es capaz de generar. Esto es así porque según aumenta para el capital social global su composición orgánica y técnica, aumenta también con ello la tasa de plusvalor (mayor va siendo la proporción del trabajo excedente frente al trabajo necesario), pero no aumenta en cambio la masa total de plusvalor en la misma proporción, dado que el trabajo necesario (el que al trabajador se le paga para reproducir su fuerza de trabajo) que resta por capitalizar va disminuyendo drásticamente según avanza esa inversión y composición orgánica del capital. Dicho de otra 
manera, el trabajo necesario disminuye en la misma dimensión que crece el trabajo excedente (es decir, el que trabajan los productores exclusivamente para la ganancia de quien compra su fuerza de trabajo). Y conforme disminuye ese trabajo necesario es más costoso apropiarse del trabajo necesario que va quedando.

Con ello la Tasa General de Ganancia Media tiende a descender, independientemente de que unos determinados capitalistas puedan aumentar su tasa de ganancia ${ }^{1}$.

Esto va dando como resultado una creciente sobreacumulación de capital en relación a su capacidad de generar ganancia. Proceso tendencial que se agrava con la aceleración de la propia competencia técnica intercapitalista y la trepidante batalla en torno al $\mathrm{I}+\mathrm{D}$, que deviene cada vez más onerosa, dado que la rápida caducidad tecnológica no permite la satisfactoria amortización del capital invertido ${ }^{2}$.

Sin embargo, esa tendencia, que está siempre ahí larvada, no tiene porqué manifestarse necesariamente en forma de cataclismos capitalistas. De hecho, históricamente ha sido contrarrestada a través de numerosos factores y procesos, tantos que a menudo aquélla pareciera no tener ninguna manifestación real concreta, y ha llevado a buena parte de científicos sociales, incluso críticos, a negarla. La monopolización, la guerra, la expansión de la frontera y la posible formación de nuevos centros de acumulación preferencial, fueron los procesos contratendenciales de tipo "macro". Igualmente lo fueron muchos otros procesos puestos en marcha para contrarrestar la crisis de valorización del capital (aumento de la tasa de explotación

${ }^{1}$ Tengo que remitir aquí para la explicación pormenorizada de estos detalles, así como para la bibliografía justificativa, a Piqueras (2011a y 2014a). De todas formas, puede encontrarse el más asentado desarrollo de estos presupuestos marxianos en Grossmann (1979).

${ }^{2}$ Fijémonos en que la obsolescencia programada de la tecnología (acortar la vida media de la misma como valor de uso) viene sustentada por el supuesto aumento en los beneficios que debe deparar la aceleración en la renovación tecnológica. En realidad esa aceleración conduce a la depreciación de la tecnología (Dekle, 1994; Hornstein y Krusell, 1996). El resultado en la tasa de beneficio no se percibe, sin embargo, hasta el final del proceso. Veamos. Con la innovación tecnológica disminuye la edad media de la tecnología empleada, es decir, se reduce la vida media del stock de capital fijo. Conforme se reduce la vida media de la tecnología utilizada, el tiempo de producción disponible para transferir su costo al producto disminuye también. A partir de cierto punto, el costo de mano de obra por unidad de capital fijo empleado ya no disminuye sino que más bien aumenta, es decir, el costo de renovación aumenta más de prisa de lo que disminuye el costo laboral (con una vida media teórica del capital fijo tendente a cero, el costo laboral por unidad de capital fijo tendería a infinito). Con ello baja la tasa de retorno y se desmiente el supuesto de que la innovación tecnológica y la consecuente baja en la edad media de la tecnología conllevan a una mayor capacidad competitiva. El capital se desplaza entonces a aquellos lugares donde el desarrollo tecnológico es menor y también es más lenta la velocidad de sustitución tecnológica (formaciones periféricas), con menor precio, asimismo, de la fuerza de trabajo (Diercxksens, 2012; Dierckxsens y Jarquín, 2012). 
de la fuerza de trabajo, abaratamiento del coste de las materias primas y también del empleo del capital constante, elevación de los tiempos de rotación del capital y de su renovación, así como el reciente intento de “inmaterialización” de la economía o reducción sustantiva del peso del capital fijo en ella, entre otros pasos y desplazamientos que veremos más adelante).

Hay, en cambio, otro tipo de crisis estructural subyacente. Tiene que ver con las inadecuaciones entre la forma dominante de mediación social que adquiere históricamente la explotación capitalista (más o menos despótica, más o menos reformista o democrática, que se traduce en la naturaleza que adquiere el Estado en cada momento) y las plasmaciones socio-institucionales y maneras de expresar la relación de clase que permiten el valor y la forma mercancía y gestionan la fuerza de trabajo de cara a optimizar su consumo productivo (es decir, la generación de plusvalía por mediación de aquélla). Estas inadecuaciones se traducen en crisis de regulación.

Cuando las crisis de regulación coinciden con las crisis de valorización provocan grandes conmociones internas del capitalismo, que le hacen mutar y, al fin, pueden poner en peligro su propia continuidad. Estamos en presencia, entonces, de las Grandes Crisis o Crisis de Larga Duración.

Éstas dejan indefectiblemente atrás una generalizada desvalorización de capitales (los menos "competitivos") y de la fuerza de trabajo, promueven el acrecentamiento del "ejército industrial de reserva" y una gran destrucción de fuerzas productivas, así como la rápida elevación de la tasa de ganancia de los capitales supervivientes (que tienen la posibilidad, por eliminación de competencia, de aprovechar mejor los últimos avances tecnológicos). Se inicia un nuevo ciclo de acumulación, pero con diferentes formas de gestionar los procesos productivos y de establecer la mediación social. También se modifican las dinámicas de generación y apropiación del plusvalor. Es decir, estamos, según la teoría regulacionista, ante un nuevo modelo de crecimiento (un régimen de acumulación más un modo de regulación social) $)^{3}$.

${ }^{3}$ De acuerdo con las teorías de la regulación, todo régimen de acumulación alcanzará un punto de crisis en el cual el modo de regulación no podrá sostenerse, y las elites estarán forzadas a encontrar nuevas reglas y normas, pergeñando un nuevo régimen de acumulación, que estará vigente hasta que desarrolle su propia crisis, y así sucesivamente Ver, por ejemplo, los clásicos Aglietta (1982), Boyer (1992), Boyer y Saillard (2002).

Sin necesidad de asumir el conjunto de implicaciones de esta escuela teórica, sí se concuerda en este artículo que el capitalismo debe redefinir periódicamente el modo concreto en el que opera para responder a la concreción histórica de sus contradicciones básicas, a sus distintas manifestaciones y aristas. Al responder a la cambiante manifestación de esas contradicciones también de manera diferente en cada momento, el capitalismo cambia su forma. 
Las Crisis de Larga Duración trastocan asimismo la geografía de la acumulación, modificando la primacía en la dinámica de acumulación hacia otras localizaciones. Lo que históricamente ha abierto la posibilidad a reconfiguraciones de la División Internacional del Trabajo.

El capitalismo histórico ha padecido dos Grandes Crisis, de Larga Duración, que se separan entre sí por un siglo de distancia y que han dado lugar a dos cambios sistémicos de modelos de crecimiento o Grandes Mutaciones capitalistas. La primera Gran Crisis comenzó en los años 70 del siglo XIX y, tras un breve repunte ascendente de mediados de los años 90 del siglo XIX hasta mediados de los años 10 del XX, convulsionó el planeta entero: dos Guerras Mundiales, un derrumbe económico generalizado en las formaciones sociales capitalistas, el mayor crack bursátil conocido por al capitalismo hasta hoy y también la mayor ruptura habida con el mundo capitalista, la Revolución Soviética ${ }^{4}$. Igualmente desembocó, en las formaciones sociales centrales del capitalismo mundializado o Sistema Mundial, en la mutación más grave experimentada por este modo de producción hasta nuestros días. El capitalismo renunció a parte de sí mismo, para pasar a estar cada vez más asistido por el Estado a través del Departamento III o de servicios sociales, encargado de absorber la plusvalía que los otros dos (el de producción de bienes de equipo y el de producción de bienes de consumo, no podían reinvertir de cara a la acumulación). Esto lo transformó en un capitalismo social, es decir un híbrido, que es el que subsistió de forma dominante hasta los años 70-80 del siglo XX en los núcleos centrales de acumulación del Sistema y cuyo “código reformista” permitió la supervivencia del mismo.

La segunda Gran Crisis se ha producido exactamente un siglo después, a mediados de los años 70, y la arrastramos hasta la actualidad con todo el fardo dramático que ello implica, el cual va incorporado a la nueva drástica mutación en curso del capitalismo.

Con la Primera Gran Mutación el capitalismo emprendería un ciclo virtuoso de acumulación en sus formaciones centrales a costa de violentar la propia razón de ser capitalista, mediante la trasmutación del Estado en una entidad crecientemente interviniente en la economía y la metamorfosis por tanto de ésta en una "economía mixta”, funcionando a cuenta de un creciente sector social que desmercantilizaba condiciones de reproducción de la fuerza de trabajo, las cuales quedaban convertidas en "servicios sociales". Igualmente se desmercantilizaba parcialmente la propia fuerza de trabajo a través de sucesivos derechos socioeconómicos.

Las bases materiales de esa acumulación radicaban en un conjunto de procesos, entre los que pueden destacarse los siguientes:

${ }^{4}$ La “desconexión” soviética marcaría una nueva dinámica de luchas de clase y de reparto del valor a escala mundial, permitiendo el "capitalismo social” en las formaciones centrales, una mutación capitalista que empotraría la economía a la política y le permitiría sobrevivir por más tiempo, como se dice en el texto. He desarrollado estos puntos en Piqueras (2014a). 
1. Incorporación creciente de capital fijo (necesaria incorporación de una cantidad creciente del mismo para obtener el mismo plusvalor absoluto)

2. Maximización de las ventajas de las economías de escala

3. Subdivisión del trabajo complejo en trabajo simple en la cadena de montaje

4. Aumento continuo de la productividad del trabajo y del capital (producto por unidad de capital invertido)

5. Indexación de los salarios al aumento de la productividad y generación masiva de empleo (lo que implicaba la "interiorización" de la lucha de clases en la acumulación)

Por su parte, la intervención esencial del Estado tenía lugar en los siguientes términos:

1. Convirtiéndose en factor vital de demanda mediante la intervención directa (Estado-empresario) o indirecta (posibilitando mercados para la empresa privada);

2. Adoptando medidas proteccionistas en el plano internacional, respecto de los sectores estratégicos propios y el empleo doméstico;

3. Realizando una política monetarista moderadamente expansiva e inflacionaria;

4. Estableciendo una política fiscal progresiva, con cierta sensibilidad respecto del principio de equidad contributiva.

Todo ello estaba enmarcado en un contexto mundial de desarrollo de los mercados oligopólicos, basados en una gran centralización del capital, con las jerarquías y divisiones del trabajo correspondientes. Jerarquías y divisiones que fueron amparadas por el sistema de Bretton Woods, promovedor de cambios fijos de monedas basados en la función de moneda internacional desempeñada por el dólar norteamericano.

A su vez ese marco internacional fue posible por la hegemonía incontestable de E.E.UU. en todos los ámbitos, garantizando que las rivalidades económicas intercapitalistas no derivaran en guerras militares en el núcleo duro del Sistema.

\section{La Larga Crisis del fin del siglo XX y principios del XXI}

El capitalismo parecía haber encontrado la piedra filosofal del crecimiento sin crisis. Un ciclo virtuoso de producción-consumo-producción... aparentemente sin fin ${ }^{5}$.

\footnotetext{
${ }^{5}$ Obviamente este ciclo estuvo indisociablemente ligado a una división internacional del trabajo comandada por las formaciones centrales del Sistema Mundial capitalista, que emprendieron un neocolonialismo amparado en la suerte de "supraimperialismo" que ejercía EE.UU., de cara a la acaparación y explotación de los recursos planetarios, la obtención de
} 
Pero su enfermedad crónica se encontraba latente en todo el ciclo. Si ya en los últimos años 60 empezaron a darse manifestaciones evidentes de ella, que fueron de la mano del mayor ciclo de movilizaciones sociales de la Postguerra, a partir de los primeros años 70 del siglo XX se instaló de forma inocultable.

Algunos procesos desfavorables para la reproducción ampliada del capital se sumarían a la ya explicada sobreacumulación capitalista especialmente a partir de la fractura de 1968-1973, pues las propias enormes inversiones en capital fijo que se habían producido habían acrecentado la vulnerabilidad de la tasa de ganancia, ya que:

- Se produjo una saturación nacional de la demanda, especialmente de bienes de consumo durables, con el consiguiente rebrote de la sobreproducción.

- Creció la competencia intercapitalista en la renovación del ciclo tecnológico, lo que acabó favoreciendo también la caída de la rentabilidad y de la inversión.

- Se alcanzó un límite de los ajustes keynesianos para compensar los desequilibrios. La gestión keynesiana de la demanda con creciente endeudamiento público, así como estímulos fiscales e ingente cantidad de crédito a disposición de empresas y familias para sostenimiento del poder de compra, conservaba la economía en marcha, pero aumentaba al tiempo el exceso de capacidad del sistema, manteniendo el capital menos competitivo y obstaculizando la recuperación de rentabilidad. Como consecuencia, la acumulación de capital en forma de instalaciones, equipo y software siguieron menguando, y con ello se frenó también el aumento de los salarios y del gasto social.

- La interpenetración creciente de los sistemas productivos con la segunda onda globalizadora capitalista, redujo enormemente la eficacia de las políticas macroeconómicas tradicionales, al introducir una generalizada competencia basada en nuevas formas de gestión y consumo de la fuerza de trabajo, que abandonaban la cadena en serie en favor de una desconcentración productiva y una tecnología multifuncional para la producción simultánea de diversos productos (Just in time). Las “economías de

valor a escala global y, en definitiva, la concentración y centralización del capital. Lo que quiere decir que sus correlatos infaltables a escala mundial fueron el derroche de recursos y energía ("crecientismo”) y el militarismo (la sobredimensión de la industria y el aparato militar de buena parte de los Estados, con la excepción entre los centrales de Alemania y Japón que, al medrar bajo el paraguas militar norteamericano, se vieron libres de esos gastos improductivos, viendo favorecida su rentabilidad económica).

A escala interna de cada formación social, el ciclo expansivo se sostuvo siempre en la división sexual del trabajo y en la exogenización (o exclusión de la derechos laborales y/o sociales) de determinados sectores de población (mujeres, inmigrantes, ciertas poblaciones marginales...). 
gama” se fueron abriendo paso frente a las "economías de escala”, y el trabajo en equipo funcional o "línea de arranque" frente a la cadena de montaje del trabajador masa. Al tiempo que la interpenetración global de los mercados estableció una única fuerza de trabajo mundial con diferentes precios, lo que conllevó un ingente "ejército laboral de reserva" de dimensión mundial (el cual se amplió todavía más con la caída del bloque soviético y la entrada de China en la OMC), que contribuyó a debilitar drásticamente el poder social de negociación de las poblaciones asalariadas en casi cualquier lugar del planeta.

- Todo ello coincidió con un contexto de crisis energética.

El conjunto de factores descritos quedaron más o menos "larvados" durante cierto tiempo hasta que una concatenación de interferencias económicas se manifestó de forma más visible para desbaratar el delicado mecanismo de relojería keynesiano.

Para empezar, los sustanciales y acelerados aumentos de productividad hicieron cada vez más difícil mantener el principio del pleno empleo (sencillamente no se necesitaba ya tanta mano de obra), y con ello la vinculación de los salarios a la creciente productividad ${ }^{6}$.

Por otra parte, los gastos del capital variable habían ido aumentando a consecuencia del incremento del poder social de negociación de la fuerza de trabajo. Además, la elevación de la renta de los asalariados exigía una mayor diversificación del consumo, debilitando el rígido esquema fordista de producción. Para colmo el Estado había comenzado a sobrepasar su papel de "agente intermediario" para erigirse en agente económico activo de primera instancia, dedicándose a la producción de los bienes públicos demandados por la sociedad y "transgrediendo" con ello el terreno del capital privado, que se veía así privado de un campo de ganancia cada vez más grande: lo público.

En adelante, recuperar ese espacio se convertiría en una de las principales obsesiones del gran capital privado.

En la esfera internacional, el sistema de Bretton Woods se tambaleaba desde que EE.UU. se había hecho enormemente deficitario no sólo frente a las otras dos potencias económicas, sino a escala global (como principal deudor) desde el momento en que su capacidad de imprimir su dinero a voluntad como moneda de cambio mundial había excedido su capacidad de respuesta mediante sus propias reservas, y desde que había inundado de dólares las economías europeas para pagos

\footnotetext{
${ }^{6}$ Si la productividad crece por ejemplo un 5\%, y si ni la jornada de trabajo ni la eficiencia del mismo se modifican, la producción ha de crecer al mismo nivel para mantener el empleo. Pero para ello el consumo se ha de intensificar o digamos que el conjunto de la vida ha de hacerse cada vez más compatible con el consumo continuo (ver Anisi, 1995). Y así se hizo hasta donde se pudo. Pero a la postre el consumo se mostró incapaz de seguir el ritmo requerido por la producción capitalista.
} 
e inversiones y éstas habían empezado a reclamar una parte creciente de esos pagos en oro.

Ante tamaño atolladero y la pérdida de eficacia de los mecanismos anticíclicos keynesianos se empezaron a dar las condiciones propicias para abrir el camino a iniciativas de represión de la demanda y regresión fiscal, combinadas con políticas recesivas y de control del déficit y de la inflación, así como de fomento de la financiación privada. Serían las que presidirían en adelante por doquier las estrategias de gobierno de un capitalismo que iniciaba su dimensión transnacional.

Empezaba así una nueva intervención masiva del Estado en favor de una acumulación capitalista que (de nuevo) no mostraba fuelle por sí misma. Pero ahora esa intervención se realizaba, con todo tipo de medidas, del lado de la oferta.

Para encastrar todo ello de forma más o menos coherente había que buscar un nuevo modo de regulación que conllevara una ruptura de lo que llegó a concebirse como "pactos de clase" en las sociedades centrales, (especialmente en el punto de indexación de los salarios a la productividad y en el objetivo del "pleno empleo"), aunque con ello se tuviera que actualizar la doctrina político-económica fundacional del capitalismo. De esta forma cobraría vida el neoliberalismo, que si bien ha dejado muchas dudas sobre su capacidad de propiciar acumulación sostenida, inclinó drásticamente la distribución del plusvalor en favor del Capital, favoreciendo una enorme concentración de la riqueza. Le compensaba, así, de alguna manera, de la falta de rentabilidad productiva. No hubo que esperar mucho para evidenciar los resultados procíclicos que ello entrañaba, más allá de las devastadoras consecuencias sociales.

El shock financiero-bancario de los años dos mil no es sino el resultado del fracaso en los intentos de escapar de la Segunda Larga Crisis, comenzada hacia 1973 y sólo parcialmente esquivada ${ }^{7}$ mediante la nueva mutación capitalista hacia un capitalismo híbrido, pero ahora basado en la exclusión y la crisis (y también a escala mundial en la guerra) como maneras no sólo de gestionar la relación CapitalTrabajo, sino en general la vida de las poblaciones, así como de convertir la Política en administración, eliminando la dimensión social ("keynesiana”) del capitalismo híbrido anterior.

Tenemos, entonces, que la salida a la Primera Gran Crisis sistémica se realizó mediante todo un conjunto de dispositivos económicos e institucionales tendentes a desarrollar la demanda, a través de un capitalismo híbrido que se vio forzado a reconocer a su fuerza de trabajo como ciudadana. La salida a la Segunda Crisis de

${ }^{7}$ La reestructuración o restauración pseudoliberal no pudo aumentar los indicadores de crecimiento. En los años 60 del siglo XX el crecimiento fue de 3,5 puntos, y de 2,5 en los 70 con políticas keynesianas, En los 80 fue de 1,4 y en los 90 de 1,1, con políticas neoliberales (de hecho, en plena ofensiva neoliberal de los años 80 las economías centrales que más crecieron fueron las menos neoliberales, véase, Alemania y Japón (Chesnais, 2008); datos muy similares proporciona el Banco Mundial-). 
Larga Duración se ha venido llevando a cabo mediante procedimientos contrarios: deprimiendo la demanda (al menos su capacidad adquisitiva real) y manteniendo indirectamente sectores de ella a través del crédito-endeudamiento y la participación en la especulación financiera, como enseguida veremos.

Esto último indica cuanto menos que la reestructuración neoliberal capitalista presenta también en la actualidad una relación harto problemática con el consumo o la esfera de realización de la ganancia.

\section{El neoliberalismo financiarizado. ¿Nuevo modelo de crecimiento?}

Al atascarse el proceso en el circuito primario de acumulación (donde se produce plusvalor según una dinámica de reproducción ampliada y donde los ciclos de valoración están en función de la producción y circulación de mercancías), se tienden a priorizar o acentuar tres tipos de desplazamientos: uno espacial dentro del circuito primario de acumulación, otro espacio-temporal hacia el circuito secundario y terciario de acumulación y un tercero absoluto, buscando la ganancia fuera de la acumulación, es decir, fuera de la producción ${ }^{8}$.

1. El desplazamiento espacial se realiza hacia lugares donde la composición técnica del capital es menor y por tanto el peligro de sobreacumulación no es inminente. Hacia territorios "periféricos" dentro de cada Estado y hacia las periferias del Sistema, en un movimiento hacia las localizaciones con mejores condiciones de inversión (cercanía de materias primas, exacciones o ventajas fiscales, una fuerza de trabajo con menor poder social de negociación y más barata, etc.).

2. Aquel capital se exporta bien en forma de inversión directa (repatriándose casi todas las ganancias), bien en forma de préstamos que aseguran el cobro de intereses a futuro (así como de intereses de intereses, etc. $)^{9}$.

3. El desplazamiento temporal del capital excedente consiste en que los flujos de capital se alejen del terreno de la producción y el consumo

\footnotetext{
${ }^{8}$ Estos desplazamientos acompañan al desplazamiento técnico-organizativo (hacia nuevas líneas de producción, uso de nuevas tecnologías, etc.) y al desplazamiento entre ramas o incluso sectores de actividad, que están permanentemente presentes en las dinámicas de acumulación y competencia capitalistas. El conjunto de procesos aquí descritos son sólo una parte de los que se pusieron en obra para contrarrestar la caída de la tasa de ganancia tanto en el ámbito de la valoración como en el de la realización (ver para mayor detalle y bibliografía sobre los mismos Piqueras, 2011a y 2014a). Aludo aquí a estos desplazamientos por su importancia en la configuración del nuevo capitalismo que surgiría en adelante.

${ }^{9}$ La llamada "cooperación para el desarrollo” ha sido una de las vías potenciadas para coadyuvar a ambos procesos.
} 
inmediatos (circuito primario de la economía), para invertir en infraestructura productiva a ser rentabilizada en un futuro más o menos lejano (circuito secundario de la economía: instalaciones, capacidad de generación de nueva energía, nuevas vías para el traslado de mercancías y fuerza de trabajo, etc.), o bien en gasto social que favorezca la investigación y el desarrollo y, en general, la cualificación de la fuerza de trabajo en el porvenir (circuito terciario de la economía) ${ }^{10}$. Sin embargo, en la actualidad ese desplazamiento temporal está siendo integrado en un tipo de desplazamiento espacio-temporal, en el que la inversión se dirige a ámbitos del circuito secundario que no representan una fuente de inversión productiva a futuro, sino especulativa, como verbigracia los mercados del suelo, vivienda e hipotecario.

4. El desplazamiento financiero implica una especie de trasmutación de los medios de acumulación de capital por la que el proceso de valorización mediante la producción de valores de cambio y la consiguiente reproducción ampliada del capital (D-M-D’), es subordinada a la vía monetaria de realización de la ganancia (D-D'), desatando el movimiento más ficticio e irreal de la acumulación capitalista, el espejismo de que el dinero "produce" dinero por sí mismo, sin la mediación del trabajo. El capital financiero especula al alza con la realización de beneficios futuros (hipotecando el presente a costa del futuro).

5. Esta será no sólo una forma de "huir" de los conflictos laborales y de buscar mantener la ilusión de la acumulación cuando cede la masa de ganancia, sino que, cuando aquélla se extiende e intensifica, se erige también, como veremos, en una forma de biopoder (Lucarelli, 2009), capaz de regular el conjunto de la vida social. Ha contribuido asimismo, por tanto, a los procesos de colonización interna de la fuerza de trabajo ampliamente descritos por la bibliografía sociológica (por ejemplo, Alonso, 1999 y 2007; Alonso y Fernández Rodríguez, 2014; Bilbao, 1995 y 2000; Castel, 1997).

La financiarización apuntala y refuerza, además, los otros desplazamientos, como veremos enseguida. Pero primero me detendré en la imbricación de la financiarización con las nuevas formas de acumulación y en su explicación en cuanto que propia vía de valorización, de gestión de la fuerza de trabajo y de gobernanza social.

${ }^{10}$ La inmediatez y cortoplacismo del “interés” de los diferentes capitalistas, nunca les permitió terminar de apostar abiertamente por este desplazamiento temporal de la ganancia, por lo que tuvieron que recibir el "empujón” de la lucha de clases que posibilitó que el Estado (como "capital colectivo") asumiera esas tareas con muy diferente entusiasmo en unas y otras sociedades. Naredo (2006) ha trabajado bien la dinámica y consecuencias de estos desplazamientos. 


\subsection{Redefinición de las formas de financiación}

Los mercados financieros fordistas facilitaban la actividad del intercambio final, es decir la realización del mecanismo de acumulación capitalista sin interferir demasiado ni en la fase inicial de financiación (que dependía en gran medida de la Banca), ni en las decisiones sobre producción ni en la esfera de la distribución funcional de la renta.

Esto era posible porque la actividad productiva era financiada por el sector crediticio-bancario, porque la producción material era el motor de la acumulación a través de la explotación del trabajo asalariado y porque la definición y recomposición de las políticas económicas se realizaba de manera bastante autónoma, en el espacio nacional-estatal.

La pérdida de importancia de estos tres factores fue liberando a los mercados financieros de su subalternidad en el proceso de acumulación fordista-tylorista. Así, la reducción de la autonomía nacional-estatal y de las políticas de regulación del sistema de cambios; el paso de tecnologías mecánicas que incorporaban altas ratios de capital fijo a tecnologías "inmateriales" del conocimiento; y la desmaterialización de la moneda (desvinculación de la moneda respecto de cualquier tipo de mercancía) así como su definitivo desenganche del oro, proporcionaron las condiciones objetivas de salida del proceso de financiarización, que fue ayudado por factores indirectos o exógenos, como la crisis económico-política del modelo de desarrollo fordista-keynesiano y el consiguiente derrumbe del sistema de BrettonWoods, seguido del giro monetarista de la principal economía del planeta.

Otros factores endógenos terminaron de coadyuvar el proceso: la informatización de los intercambios bursátiles (que permitió multiplicar las transacciones en tiempo real), los fondos de pensiones y la aparición de los productos derivados (que no tienen valor en sí, sino un "valor" convenido a través de expectativas de futuro de otros productos financieros preexistentes). Se liquidaba de ese modo el monopolio crediticio de la Banca (sobre estos mecanismos financieros, véase Fumagalli, 2010).

Paulatinamente, también, cada vez más Estados, como los de la UE, dejan de financiarse a través de sus Bancos Centrales, para hacerlo en mayor proporción mediante los mercados financieros, desviando así la especulación sobre las monedas hacia las deudas públicas ${ }^{11}$.

${ }^{11}$ La creación de los Bancos Centrales estuvo presidida por el interés de enfrentar las crisis financieras y de impagos, tanto de la Banca privada como del Estado. El Estado garantizaba la capitalización del Banco Central, el cual, en contrapartida, hacía las veces de prestamista de última instancia tanto del propio Estado como de los Bancos privados. Eso se rompió en la creación de la UE, pues en adelante el Banco Central Europeo no iba a prestar a los Estados, sino a los Bancos privados, a un interés muy bajo, que es multiplicado en ocasiones hasta por 12 veces cuando esos Bancos después prestan a los Estados. Éstos 
En adelante, en general, la acumulación capitalista va a depender cada vez más de los mercados financieros y menos de las políticas públicas estatales y la gestión de la deuda pública. De hecho, la relación entre mercados financieros y política monetaria se ha invertido en este periodo. Lo que en el keynesianismo era controlado, las finanzas (como mera asignación del ahorro, subalterna al mercado crediticio), se ha convertido en el controlador, ya que las plusvalías financieras son ahora la base de la asignación y suministro de las inversiones. La política monetaria ha pasado a ser "un soporte subalterno de la lógica financiera global” (Fumagalli, 2010: 81). Y ésta ha presentado hasta la crisis de 2007-2008 una fuerte simbiosis con las nuevas tecnologías inmateriales, logísticas, de dirección y comunicación.

Entonces, una vez conseguida la dependencia de los principales agentes económicos (Estado, Banca, empresas) frente a los mercados financieros, se trataba de alzar formidablemente las tasas de interés real (esto es, muy por encima de la inflación), manteniéndolas lo más elevadas posible en el tiempo. Se generaban así endeudamientos acumulativos de los Estados (deuda pública) o países (deuda externa) a partir de acumulación de deudas preexistentes (origen de la "crisis de la deuda" de las formaciones periféricas de los años 80). El capital transnacional construía de esta forma un dispositivo de polarización extrema entre deudores y acreedores, que iba acompañado de la imposición de nuevos criterios de gestión, con la liberación de enormes flujos de dividendos, mientras que se abrían nuevos canales de remuneración de las oligarquías a cargo de la gestión del nuevo modelo de crecimiento (con cada vez más difuminadas fronteras entre gestión y propiedad, entre ingreso, retribución, beneficio o plusvalía; todo lo cual abrió además el camino a una suerte de institucionalización de la corrupción). Para guarecer esas enormes ganancias se creaban por doquier "paraísos fiscales", al tiempo que la fiscalidad sobre los ingresos más altos era sustancialmente reducida (para el desarrollo de estos puntos, véase Duménil y Lévi, 2006).

Pero dado que con los intentos de solución de los problemas en el ámbito de la valorización (debido a la sobreacumulación), se agravaban en cambio los mismos en la esfera de la realización (por depresión de la demanda paralela a la creciente desigualdad social y la concentración de la riqueza ${ }^{12}$ ), con el proceso de financiari-

además tienen que sacar títulos de deuda a la Bolsa, para financiarse, exponiéndose a los mercados financieros como un agente particular más.

${ }^{12}$ En su informe sobre la participación de los salarios en el producto nacional, la OIT informaba en 2012 que en 16 economías de capitalismo avanzado la participación salarial media decayó del 75\% del producto nacional en mitad de los años 70, al 65\% en los años justo anteriores a la crisis de los años 2000, volviendo a decaer a partir de 2009. En otras 16 economías "en desarrollo" o "emergentes” estudiadas, el informe señala que esa participación media de los salarios cayó del 62\% del PIB en los primeros años 90, al 58\% justo antes de la actual crisis (OIT, 2012). Oxfam publica el 20 de enero de 2014 un informe que desglosa cómo ha crecido el porcentaje de participación en la renta del 1\% más rico de la 
zación de la economía se buscaba una salida diferente: que las dinámicas de valorización y realización del capital tendieran a converger, dándose el empotramiento de los tres principales momentos del proceso económico capitalista: financiación producción - realización. Se perseguía en adelante la resolución de los tres a la vez y con la mayor inmediatez posible.

Sin embargo, todo este entramado se ha evidenciado altamente inestable por numerosas razones. La principal es que está sustentado en una gran bola de capital ficticio ${ }^{13}$, más y más distanciado de la "riqueza real" contabilizada según los propios términos capitalistas. Como consecuencia de ello, incorpora otra gran debilidad, que es depender de convenciones. Éstas no son sino mecanismos de generación de expectativas tendentes a homologar comportamientos basados en la racionalidad mimética, dependiente a su vez de la propaganda, del lenguaje público-institucional

población en 24 de los 26 países que tienen registrados estos datos (The World Top Incomes Database). A escala global señala que el 10\% más rico del planeta posee el $86 \%$ de los recursos, mientras que el $1 \%$ acapara cada vez más cerca de la mitad de la riqueza mundial (Oxfam, 2014).

Sobre estos temas y sus consecuencias hay buenas reflexiones fundadas en 15 años de investigaciones por un equipo internacional sobre 3 siglos de desigualdades en 20 países, en el recién aparecido pero ya tan ampliamente difundido como contestado trabajo de Piketti (2013).

${ }^{13}$ El capital a interés produce una ilusión social de doble sentido, cual es que toda suma de dinero genera una remuneración y toda remuneración en interés está sustentada en un capital real. El verdadero problema con esta ilusión ocurre cuando se titularizan los derechos de remuneración de deudas e intereses. Es decir, cuando comienza a comercializarse un capital que es deuda y que en realidad no existe (esta es la base de su ficción, que después las finanzas complejizarán sobremanera). Sobre la definición y explicación pormenorizada del concepto de capital ficticio y su enorme sobredimensión actual, pueden consultarse Carcanholo y Nakatani (2000); Marques y Nakatani (2009) y Carcanholo (2009 y 2011).

El Bank for International Settlements, en su Quarterly Review de junio de 2011, reportaba haber recibido datos bancarios hasta diciembre de 2010 por un total de 601 billones de dólares en derivados emitidos, lo que suponía más de 10 veces el PIB mundial. Otras fuentes estiman, sin embargo, ese monto de capital ficticio en torno a 30 veces la riqueza mundial "real". En cualquier caso, en 2012 el Banco de Basilea confirmaba que el monto total de derivados financieros superaba los 720 billones de dólares, lo que suponía un crecimiento de un 20\% en poco más de un año (Dierckxsens y Jarquín, 2012:40).

Recordemos, a tenor de la enorme masa de capital ficticio creada, la advertencia de Arrighi (1999) de que cada vez que sucede la prevalencia del capital financiero sobre el productivo y el mercantil en el reparto de la plusvalía quiere decir que un determinado modelo de crecimiento y la potencia que se ha hecho hegemónica con el mismo, entran en su fase decadente. Estamos en estos momentos sumidos en la segunda fase universal de financiarización del sistema capitalista, tras la que surgió con la Primera Gran Crisis sistémica. 
y la consiguiente "industria de la creación de pensamiento y opinión” que le es aneja, entre otros factores análogos (Lucarelli, 2009). Las convenciones, sin embargo, paradójicamente, no pueden escapar de la variabilidad y ciertas dosis de imprevisibilidad de los comportamientos sociales (la emergencia e incertidumbre de la teoría de la complejidad se hacen en el capitalismo financiarizado más evidentes).

Pero veamos más de cerca la vinculación entre financiarización y los otros tipos de desplazamiento que han presidido hasta ahora la fase neoliberal de "huída" de la crisis.

\subsection{Financiarización económica y circuitos secundario y terciario de acu- mulación}

La derivación de la inversión capitalista hacia el circuito secundario de acumulación, ha hecho que éste se haya convertido en un potente atractor de una parte importante de los flujos financieros globales en busca de rentabilidad. Ello ha requerido también de una enorme intervención política en todas las escalas de gobierno, desde las supraestatales a las administraciones locales (lo que habla de la sustancial modificación de las modalidades de intervención pública que ha tenido lugar con el neoliberalismo financiarizado, antes que de la extinción de las mismas). La intervención del Estado ha venido siendo dirigida crecientemente a "la regulación y estímulo de ámbitos antes considerados periféricos, como pueden ser los mercados del suelo, vivienda e hipotecario, así como la gestión de dinámicas territoriales y ambientales que ahora tienen una dimensión crucial en la reproducción del capital” (López y Rodríguez, 2010: 216). Se trata de convertir los bienes y servicios (como pensiones y viviendas, por ejemplo), así como el capital instalado y, en suma, el conjunto del territorio, en bienes de inversión, identificados como "activos" que presumiblemente están sujetos a una valorización permanente o, dicho en otras palabras, a la quimérica suposición de que siempre en el futuro valdrán más.

Estas formas de acumulación llevan consigo, por un lado, una dinámica de espacio construido, es decir, de edificación de inmuebles de todo tipo, edificios, autovías, vías férreas de alta velocidad, etc., que hacen que el nuevo modelo de crecimiento capitalista, que se presumía y predicaba "inmaterial", sea en realidad altamente energívoro y destructor ambiental.

Por otra parte, se priorizan formas de crecimiento económico que no dependen del aumento de la capacidad productiva de la hora de trabajo. Un crecimiento sin acumulación que tiene, entre otras, una consecuencia especialmente importante para la gestión de la fuerza de trabajo, y es que el salario muestra una creciente arbitrariedad en su composición, que se desconecta más y más de la medida de trabajo realizado, estando cada vez menos relacionado con cantidades concretas de tiempo relativas a unidades discretas de producción, para pasar a vincularse a la relación dentro de la jerarquía empresarial, a la promoción personalizada (que implica la competencia horizontal entre otros posibles ocupantes de esa posición), en detrimento, pues, de cualquier opción identitaria laboral colectiva. Ni que decir tiene que 
el salario aumenta también, así, su poder disciplinador, y trasluce cada vez más lo que siempre se supuso que debía ser pero que nunca terminó de realizar debido a las resistencias del Trabajo: una medida arbitraria, un simple dispositivo de movilización y sujeción de la fuerza de trabajo (sobre esto último, Piqueras 2011b; para el conjunto de lo expresado en estos puntos hay una excelente síntesis en López y Rodríguez, 2010).

El ataque frontal al pilar keynesiano de indexación de los salarios a la productividad, que fungió como pauta general en el núcleo duro del sistema capitalista mundial, puede realizarse así de forma más eficaz e impune.

Tal desvinculación del salario respecto de la productividad, la descomposición de la regulación laboral colectiva y la débil capacidad contractual del capitalismo financiarizado han conducido a una creciente individualización del salario. De la lucha por el salario como variable independiente, propia de la radicalización de la protesta del Trabajo en la fase final keynesiana, pasamos así a la dilución en aumento de la contraparte obrera en el conflicto Capital/Trabajo.

Las rentas financieras subsecuentes a la revalorización creciente de los bienes de inversión (o "activos") hacia los que se canalizó el ahorro, fueron hasta la manifestación de la crisis en 2007, sustituto, para variadas capas de la población asalariada, de la aseguración colectiva. La seguridad social, que fue objetivo y resultado de las luchas seculares del Trabajo y que conformó el núcleo duro de la mutación reformista que permitió la sobrevivencia de la acumulación capitalista durante buena parte del siglo XX, iba siendo así sustituida por mecanismos de seguro individual (lo que se llamó "keynesianismo del precio de activos"). Todo ello iría indisociablemente unido a la entelequia del individualismo propietario como convención financiera dominante ${ }^{14}$.

De la mano de estos procesos ha tenido lugar una profunda modificación de los modos de pertenencia y acceso a los derechos respecto de los de la sociedad industrial clásica, en la que el trabajo era el principal medio de afiliación social y en la que existía un consenso respecto al reconocimiento de la valía de la actividad laboral (e incluso en alguna medida, de su dignidad), que se constituía en la princi-

${ }^{14}$ Esta convención estaba basada a su vez en dos abstracciones: el mercado como lugar de decisión neutral y objetiva, y el individuo como agente económico que toma sus decisiones aisladamente, de forma racional y en pos de la maximización de su beneficio y que tiene la oportunidad de enriquecerse si se lo merece.

Efectivamente, en los mercados financieros, según se predica, todo el mundo concurre libremente, y son sólo sus habilidades y aciertos los que determinan su éxito (pues se reputan de ser los mercados “más libres”). Han sido por tanto la máxima expresión hasta hoy de la conjunción de esas dos abstracciones, que han sostenido la entelequia de la sociedad de propietarios. Pero han conseguido también altas dosis de autocontrol y el proceso de adhesión de amplias capas de la fuerza de trabajo a la individualización de las relaciones laborales y de la seguridad (López y Rodríguez, 2010). 
pal fuente de riqueza social y de posibilidades de vida de la absoluta mayor parte de la población ${ }^{15}$.

El Estado Social se constituyó en torno a la protección de esa relación laboral y a la procura de la integración disciplinada de la fuerza de trabajo implicada en ella. Por contra, la financiarización de las economías familiares, los ataques desde diferentes fuentes al salario y la dilución de la propia relación salarial consiguieron quebrar buena parte del entramado de la sociedad del trabajo.

Para crecientes capas de la población asalariada la prestación laboral fue sustituida o complementada de alguna manera por la propiedad en "activos" como fuente de renta. Por eso mismo creció la importancia del trabajo-empleo como medio destinado a la compra de activos, consiguiéndose de esta guisa un ingente trasvase de los salarios a todo tipo de instituciones y artilugios financieros. Lo cual refleja el cambio en las formas predominantes de obtención del beneficio financiero: de formas intensivas basadas en altos tipos de interés, se ha pasado a formas más extensivas sustentadas en una penetración creciente de las dinámicas financieras en el tejido social (Midnight Collectives, 2009) y en operaciones financieras basadas en el apalancamiento masivo, erigiendo a éste como importante impulsor del crecimiento.

La financiarización puede verse también, por tanto, según dijimos, como un conjunto de reglas sociales tendendes a homogeneizar los comportamientos de los individuos, como una forma de biopoder que facilita la subsunción de la circulación y reproducción social dentro del proceso de valorización (Lucarelli, 2009). Todo ese entramado se vería resentido, no obstante, al romperse la conexión virtuosa entre salarios y rentas financieras, con la materialización de la crisis en este nuevo siglo.

Lo que no se ha cerrado todavía con el modelo de crecimiento neoliberalfinanciarizado es la relación de privilegio entre la propiedad capitalista y las fracciones superiores del salariado (managers, altos técnicos o directivos más los cuadros burocráticos y/o altos responsables de la Administración pública) (Duménil y Lévi, 2006) ${ }^{16}$. Lo cual ha llevado a no pocos autores a hacer hipótesis con la posibi-

${ }^{15}$ El régimen de acumulación fordista-tylorista se sustentaba en la ética del trabajo asalariado y en la doble ligazón desarrollo-crecimiento y bienestar-ocupación, así como en la democracia en la esfera del consumo-circulación de las mercancías. Mientras que el proceso de acumulación (esfera de la producción de las mercancías -sobre todo de carácter material-) se basaba en mecanismos disciplinarios directos destinados a la subsunción real del Trabajo (Fumagalli, 2010).

${ }^{16}$ Salarios y rentas de capital parecen confundirse, distorsionando la evolución de la masa salarial y en buena medida del salario. Las plusvalías financieras, por su parte, son trasmitidas en gran medida a sus gestores, managers y altos ejecutivos por vía salarial (los working rich). 
lidad de que se esté gestando una nueva clase dominante salida del propio salariado (por ejemplo, Boltanski y Chiapello, 2002). Sin embargo, desde otra perspectiva bien pudiera ser también la forma en que la burguesía se asalariza a sí misma para incardinarse más o menos legítimamente en un nuevo modelo de crecimiento que, eso sí, continuaría en gran parte basado en la apropiación de la riqueza colectiva (Žižek, 2013) ${ }^{17}$.

\subsection{Financiarización, exportación de capital excedente y “economías emer- gentes"}

Hemos visto que lo que está en curso en la actualidad, en las formaciones centrales, es la construcción de un proceso de valorización que modifica los elementos que han constituido hasta ahora no sólo la generación de riqueza social sino la propia base de la acumulación capitalista. Queda ésta cada vez más supeditada a la dinámica de convención financiera sujeta a la revalorización de activos que, sin embargo y a pesar de las apariencias, están ligados finalmente a la plusvalía producida.

Por eso el otro gran anclaje de la financiarización, que es el que en realidad sustenta todo el castillo de naipes especulativo, es la exportación de capitales hacia las "economías emergentes", altamente intensivas en trabajo y en recursos. Esas economías proporcionan en la actualidad el principal sustentador del proceso de valor en la economía real capitalista, así como por tanto las expectativas sobre la obtención del valor futuro y la acumulación que se va a seguir produciendo (y nunca mejor dicho, "produciendo" merced a la producción). Los mercados financieros pueden permitirse el lujo de hacer crecer disparatadamente esas expectativas, pero no tendrían base para hacerlo sin la dinámica de acumulación de esas hasta ahora "periferias" del sistema capitalista mundial.

Las políticas monetarias laxas neoliberales (combinación de alta emisión de moneda, "flexibilización cuantitativa” más bajos o muy bajos tipos de interés y competencia por la devaluación monetaria), contribuyeron al exceso de liquidez y capital excedente de las economías centrales durante los años 90 del siglo pasado y comienzo de los 2000. Promovieron igualmente, en consecuencia, la afluencia de capital hacia los mercados emergentes, multiplicando los inversores internacionales

Las formaciones sociales que se especializaron en esta vía lograron escapar momentáneamente a las caídas de la tasa de ganancia propias de las economías industriales maduras. Se creían libres de sus crisis. Hasta que una de las Grandes les estalló encima.

${ }^{17}$ De hecho, la salida a luz de las vinculaciones retributivas “anómalas” entre altas esferas del salariado y la deriva financiera de la economía (con la que, recordemos, se había prácticamente instituido la corrupción), puede querer indicar cuanto menos un cambio de ciclo en el modelo de crecimiento, en el que la clase dominante va a expulsar a ciertos sectores "manageriales” de su seno. 
(fondos de pensiones, gestores de inversión, Bancos centrales y fondos soberanos) que incrementaban sus asignaciones en aquellos mercados (ostentando de paso más y más propiedad de la deuda pública de los mismos). De esta manera también el ahorro de más amplios sectores de las fuerza de trabajo de las formaciones centrales fue yendo a parar a las economías dichas "emergentes".

La propia financiarización (y por supuesto el declive de la acumulación en los centros que está causalmente conectado a ella), está en la base de la "emergencia" de esas formaciones sociales. La exportación de capitales a ellas se nutre de las expectativas de valorización de los activos emergentes en los mercados financieros, acentuando la fuga de capitales allí.

Crecieron rápidamente, así, los préstamos y la inversión especulativa en esas economías. Con unos y otra, también lo hicieron los precios de los activos, especialmente el de los bienes raíces. Las grandes afluencias de capital foráneo habían abarato allí el crédito, pero asimismo los rendimientos de la deuda soberana (el bono brasileño, por ejemplo, cayó en 10 años, de 2002 a 2012, del 25\% al 2,5\% de rendimiento).

El dinero barato de las formaciones centrales ha incidido en la deformación económica de las periferias más solventes. Más que bienes y servicios, las formaciones centrales:

“...trataron de exportar las cargas del ajuste requerido por la crisis de 2008 hacia las economías emergentes. Como un hombre a punto de ahogarse que se agarra a otro que apenas sabe nadar, las políticas seguidas bien podrían traer consigo el hundimiento de unos y de otros, de las economías desarrolladas y de las economías emergentes.” (Das, 2013:1)

Tengamos en cuenta que el crecimiento alimentado por la deuda en las economías centrales (especialmente EE.UU. y UE) durante los 90 y comienzo de los 2000, impulsó las "economías emergentes" gracias tanto a la mencionada externalización de la producción, como a la importante demanda para sus exportaciones que significaba el propio crecimiento de las economías centrales.

Pero al frenarse esa onda expansiva por apalancamiento en las formaciones centrales, a partir de 2007-2008, estas exportaciones se vieron afectadas y las formaciones periféricas en alza recurrieron también al crédito, incluso de doble dígito, para impulsar la actividad económica.

Las salidas de capitales preocupados por la ralentización del crecimiento y por el calentamiento de las burbujas bursátiles, de bienes raíces y grandes infraestructuras en las "economías emergentes", dejan al descubierto serios problemas en su sistema financiero, déficits por cuenta corriente y comerciales, caída de sus reservas de divisas, reducción de la cobertura para sus importaciones y empréstitos a corto plazo combinada con una todavía alta dependencia de financiación externa, fuerte apalancamiento de sus grandes empresas, así como deficiencias estructurales de sus mercados internos, con enormes desigualdades sociales y consiguiente incapacidad de generar una demanda solvente generalizada (sobre estos puntos, véase Das, 2013; y Bond y Khadija, 2013). 
En todo ello la excepción parcial es China. Quizá la única formación social en condiciones de emprender una vía real de salida de la periferización. De hecho, la "emergencia" de los restantes países se debe también a la enorme demanda de sus recursos por parte de China (proveedores de recursos para ella). China es asimismo el único Estado con proyecto geoestratégico propio, con la reciente posible excepción de Rusia, que conserva su poder militar y cuenta con la vastedad de su territorio y fuentes energéticas, y que tras el fallido intento de aproximación a Europa, está buscando un nuevo rumbo como potencia.

Sin embargo, aunque las formaciones centrales han aceptado el determinante papel de China para contrabalancear el actual régimen de inestabilidad mundial, eso no quiere decir necesariamente que entremos en una nueva fase de acumulación centrada en China. Para empezar porque este país depende del crecimiento (y del propio avance tecnológico) de los centros del Sistema Mundial, sobre la que continua bastante rezagada (y no olvidemos que nunca una economía tecnológicamente menos desarrollada ha sustituido como hegemón a otra más desarrollada en ese sentido). Además, una acumulación china basada en su propio mercado doméstico requeriría de profundos cambios en su estructura productiva, lo que entraría en contradicción no sólo con sus actuales tasas de crecimiento sino probablemente con el propio crecimiento mundial, pues una profunda transformación sociopolítica para construir una demanda doméstica compensatoria del decline de las economías centrales, arrojaría serias dudas sobre si permitiría crecer al país lo suficiente para estimular una recuperación mundial dentro de los parámetros del capitalismo, es decir, sustituyendo a EE.UU. como el gran comprador del mundo e invirtiendo el actual partenariado chino-norteamericano (lo que quiere decir que China se tendría que hacer, entonces, necesariamente, el principal deudor del mundo, con el lastre que ello le acarrearía). Pronto alimentaría, además, la tendencia a reproducir aceleradamente el proceso de sobreacumulación. De hecho, el 'stock' de capital fijo en este país se incrementó al vertiginoso ritmo del 11,8\% por año entre 1995 y 2001, mientras que la tasa de crecimiento de empleo bajó de 2,4 a 1,2\% en el mismo periodo.

China y el conjunto de los BRICS pueden haber modificado hoy, en cualquier caso, la proporción de concentración de capital a escala mundial, pero no han podido afectar todavía de manera decisiva la centralización del mismo ${ }^{18}$.

${ }^{18}$ Así por ejemplo, si la mayor parte de los activos chinos en el extranjero son títulos públicos de bajo rendimiento, lo opuesto ocurre con los activos extranjeros en China. En 2008, las corporaciones estadounidenses obtuvieron un rendimiento del $33 \%$ sobre sus inversiones en China, mientras que el rendimiento de otras transnacionales fue del $22 \%$. Por el contrario, el rendimiento de los valores del gobierno estadounidense, que componen el grueso de los activos externos de China, fue casi nulo.

Un segundo motivo que agrava la situación, es la tendencia a la depreciación del dólar, con lo que la posición neta de inversión internacional China (la diferencia entre sus activos y 
En consecuencia, con la incertidumbre de las economías periféricas que tienden a "emerger" como posibles nuevos centros de la acumulación mundial capitalista, se cierra el círculo tautológico de valorizaciones y revalorizaciones que dependen de convenciones. Lo cual suscita no pocos interrogantes, a su vez, sobre las posibilidades de continuidad del modelo neoliberal-financiarizado de crecimiento. Su viabilidad no ya en el medio sino tan siquiera en el corto plazo, viene obstaculizada por el des-acompasamiento creciente entre el valor real generado y la revalorización ficticia del mismo vía los mecanismos de financiarización económica (es decir, la contradicción entre la nueva vía de crecimiento capitalista y la riqueza real que el capitalismo es hoy capaz de generar, lo que ha ido de la mano de una enorme acaparación de riqueza por unas estrictas minorías a costa del empobrecimiento general de las sociedades, con los consiguientes problemas de disfunción en la esfera de la realización de la ganancia).

Pero entonces, ¿está emprendiendo el modo de producción capitalista un nuevo modelo de crecimiento a partir de una hipotética "inmaterialización” de la economía, desembocando en una suerte de "capitalismo cognitivo”?

\subsection{Financiarización y “capitalismo cognitivo”}

Con el término de "capitalismo cognitivo" se ha venido señalando que en el núcleo duro de las formaciones centrales crece en el conjunto del capital la parte correspondiente a lo que se ha llamado "capital inmaterial" (I+D+i, software, educación, aprendizaje, redes, salud...), el cual es incorporado al Trabajo, frente al capital material como capital fijo -que se refiere a la maquinaria-. Esto quiere decir que, entre bastantes otros elementos, aumenta en la economía la importancia de la formación colectiva, de la elevación social de la condición intelectual del Trabajo (el

sus pasivos financieros externos) se deteriora y con ella, su balance de renta por inversión. Esto revela un aspecto de extrema importancia. Aunque el resultado de la cuenta corriente global es de un amplio superávit, "este balance negativo de las rentas emerge como un indicador de quién se está apropiando de manera privilegiada de la plusvalía que genera y realiza la producción de mercancías en China. El peso del capital extranjero en los sectores dinámicos de China es abrumador. China actúa como un espacio de valorización privilegiado para el capital de las grandes corporaciones de las potencias centrales, las cuales están ubicadas 'en la cúspide de las cadenas de valor' y maximizan la apropiación del valor generado tanto en China como en el resto de economías emergentes” (Mercatante, 2013: $\mathrm{s} / \mathrm{n})$.

Eso quiere decir que persiste la dificultad para transformar en renta de activos positivos todo el superávit amasado durante décadas en el comercio exterior. Sobre China y sus dificultades, ver, por ejemplo, Chun (2006), Ríos (2007), Loong Yu (2009-2010), Jisi y Lieberthal (2012), Herrera (2014). 
general intellect o intellect difuso en la sociedad), es decir, de la difusión del conocimiento (especial "mercancía” que no se gasta con su uso, sino que se multiplica).

"El nuevo capital constante, a diferencia del sistema de máquinas (físicas) típicas de la época fordista, está constituido, junto a las tecnologías de la comunicación y de la información (TIC), por un conjunto de sistemas organizativos inmateriales que extraen plusvalor siguiendo a los trabajadores en cada uno de los momentos de su vida, con la consecuencia que la jornada laboral, el tiempo de trabajo vivo, se alarga e intensifica. El aumento de la cantidad de trabajo vivo (...) refleja la transferencia de los medios de producción estratégica (el conocimiento, los saberes, la cooperación) hacia el cuerpo vivo de la fuerza de trabajo.” (Marazzi, 2009: 44).

Para obtener beneficio de toda esa "mercancía” el Capital necesita generar una escasez artificial, es decir, poner en marcha todo un conjunto de dispositivos sobre la propiedad y distribución de aquélla (patentes, copyrights, activos...). Al mismo tiempo, regula las condiciones de privatización de la educación y del cuidado y formación en general de la fuerza de trabajo, que a la postre entorpecen el enriquecimiento de la misma desde el punto de vista de su cualificación y creación colectiva.

Estos procesos entran en contradicción con las propias posibilidades del "capitalismo cognitivo”, obstaculizándolo. También, por ello mismo, podemos decir que el proceso del valor capitalista dificulta cada vez más el avance social en la difusión libre del conocimiento e incluso en la generalización de su producción. En ese contexto el antagonismo entre Capital y Trabajo adquiere cada vez más el carácter de antagonismo entre las relaciones e instituciones de lo común (que están en la base de una economía supuestamente apoyada de forma creciente sobre el conocimiento) y la lógica de expropiación de un capitalismo con connotaciones más parasitarias.

De hecho, la renta financiera es hoy la máxima expresión de esa expropiación, la forma que sintetiza el conjunto de dispositivos rentistas de esta fase capitalista, incluso sobre el conocimiento común. A la postre el Capital se apropia de éste no sólo a través de la privatización de lo colectivo, sino también del dominio sobre la subjetividad laboral (subjetividad programada para servir a la empresa), así como mediante la precarización del trabajo en general, incluido el intelectual, y el descarte de más y más trabajadores como "superfluos"," Pero al hacerlo entorpece su reproducción ampliada.

${ }^{19}$ La candidez con que muchas de las propuestas teóricas sobre los "bienes comunes intangibles”, la "peer2peer economy”, o la “economía social”, entre otras, hablan de cómo la extensión de la comunicación y el conocimiento que promueve el "capitalismo cognitivo" puede dar paso a nuevas relaciones sociales de producción (se llega a hablar incluso de un “tercer modo de producción”-Bauwens, 2005-) , es proporcional a su desconsideración del factor de clase (dominación, explotación, desposesión, etc.) inherente al sistema en que nos 
Y es que estas tendencias entrañan, en definitiva, una reactualización y agudización de la contradicción clásica entre el desarrollo de las fuerzas productivas y la vigencia de unas relaciones sociales de producción que las entorpecen, pues cada vez más la acumulación capitalista necesita para realizarse potenciar formas colectivas (mediante el welfare) de formación del conocimiento (de las que se nutre hoy principalmente el mundo empresarial), con la consiguiente circulación libre y productiva de saberes. Pero esta necesidad choca con los requerimientos de la gobernanza social, que exigen la apropiación privada de los medios de producción y la regulación de la vida y la destrucción de los bienes colectivos y formas garantes de reproducción social ${ }^{20}$. Es decir, estamos ante una contradicción con tendencia a agravarse entre las necesidades de la acumulación y las de la regulación capitalista.

Una supuesta vía de acumulación basada en el capitalismo cognitivo precisaría de elevadísimos grados de coordinación de los capitales individuales y de las entidades estatales, pero tales condiciones no existen. Así por ejemplo, se requeriría de una inmensa innovación institucional que, para empezar, permitiera dirigir una parte importante de los beneficios a garantizar una tasa creciente de productividad social (ampliación y mejora sustancial de los sistemas públicos de educación, innovación, fomento masivo de la creatividad, la realización individual...). Esto implicaría fuertes medidas redistributivas, nuevas formas de medir la riqueza, cambios sustanciales en la forma del Estado, etc., que modificarían sustancialmente al capitalismo (Rodríguez, 2013). Al decir incluso de algunos críticos, a la postre el capitalismo cognitivo resultaría antitético con el capitalismo.

\section{Contradicciones y desafíos ineludibles}

Hemos visto algunas de las claves a las que se enfrenta el neoliberalismo financiarizado como modelo de crecimiento que se ha intentado poner en práctica a escala casi planetaria. Radican en las siguientes contradicciones:

hallamos. En consecuencia, las relaciones de poder están casi siempre ausentes de sus análisis.

${ }^{20}$ Sobre lo expresado aquí puede consultarse, entre otra, la siguiente bibliografía: Fumagalli, Lucarelli, Marazzi, Negri y Vercellone (2009), Vercellone (2010 y 2011) y Fumagalli (2010).

En cualquier caso, el llamado “capitalismo cognitivo” y las esperanzas depositadas en él participan bastante del mito de la sociedad postindustrial, dado que su extensión en la producción real mundial es muy modesta y parcial. Y lo que crece sin cesar y sin par en el mundo es el trabajo manual en condiciones pretayloristas.

Si bien, esta línea de investigación aporta reflexiones interesantes sobre posibles vías de acumulación futuras, algunas de las cuales se manifiestan claramente en la actualidad (ver, por ejemplo, Vercellone, 2004). 
- Entre regulación y acumulación (forma en que se expresa hoy la contradicción clásica entre desarrollo de las fuerzas productivas y relaciones sociales de producción)

- Entre valorización y realización (dado que la escasa recuperación de la tasa de ganancia en la producción se ha hecho a costa de una exacerbada depresión de la demanda)

- Entre el valor ficticio generado por el entramado mundial financieroespeculativo y la plusvalía real generada, que responde a un estancamiento de la rentabilidad (lo que denota una recuperación de las tasas de ganancia sin proporcional acumulación de capital).

Se pone a prueba, además, la adaptación funcional del complejo institucional y de dominación respecto del proceso de ajuste capitalista. O lo que es lo mismo, podríamos apuntar a una probable creciente contradicción entre legitimidad y formas unilaterales actuales de "regulación social" (o si se quiere, de la "gobernanza" en curso).

Para calibrar esta última contradicción y al tiempo desafío, hay que tener en cuenta que asistimos en este impasse, mientras se produce el declive del neoliberalismo financiarizado (en el que siempre han pervivido restos del keynesianismo) y no termina de coagularse ningún modelo nuevo que lo sustituya, a una profunda reestructuración de la dominación de clase y de concentración de poder entre las élites dominantes a escala transnacional. De acuerdo todo ello con la conjunción y combinación de formas "cognitivas", tyloristas y pretyloristas de explotación del trabajo que se está dando a escala mundial. Esta nueva "fase orgiástica de la explotación” genera paradójicamente un gran desaprovechamiento o desestimación de seres humanos (“sobrantes”) (Bauman, 2005) allá donde más se han desarrollado formas de finaciarización y softwerización de la acumulación; combinándose con una precarización y ultraexplotación de la mayor parte del trabajo en el mundo.

Entre otras consecuencias tales procesos denotan una dilapidación sin precedentes a escala mundial de lo que dentro de los parámetros de acumulación sistémica fue designado como "capital humano". Hecho posiblemente compaginado con "islas" de altísimo desarrollo tecnológico, donde la plusvalía la genere fuerza de trabajo superespecializada [aunque probablemente, por ello mismo, cuanto más especializada -en el know how- más ajena a la comprensión sistémica -el know that-].

Pero un modo de producción al que cada vez le cuesta más desarrollar las fuerzas productivas y generar riqueza colectiva ya no sólo a escala mundial (donde esto siempre fue evidente) sino en sus propias formaciones centrales, ve cómo se desbaratan poco a poco las bases de la legitimidad y el consenso habidos en torno a él, que radicaban precisamente en ese desarrollo de las fuerzas productivas y en su potencialidad para producir mercancías capaces de satisfacer más y más necesidades humanas y elevar el nivel general de vida.

Por el contrario, este modo de producción tiende a manifestarse (y poco a poco a percibirse) cada vez más como un régimen de (acumulación por) desposesión 
(Harvey, 2007). Hoy está al orden del día no sólo la apropiación privada del patrimonio natural y de la riqueza social y cultural acumulada a lo largo de generaciones, sino también el propio general intellect, así como las formas de producir colectivas y las formas de tenencia comunes.

Esto se ha co-implicado hasta la fecha con una nueva dimensión de las relaciones laborales tendente también hacia la privatización. Con una nueva gestión de la fuerza de trabajo que prioriza el autodisciplinamiento y la "empleabilidad" (sustituyéndose el "derecho al empleo" por la propia gestión de la supervivencia), y una nueva forma de consumo de la fuerza de trabajo que pivota cada vez más en torno a la sobre-explotación y la autoexplotación (“autónomos”, “emprendedores”...).

Pero la desposesión sin acumulación de capital tiene un corto recorrido dentro de un modo de producción que se llama precisamente "capitalista” (es decir, un capitalismo sin capital es imposible). ${ }^{21}$

Precisamente en ello radica otra gran contradicción sistémica que brota de sus núcleos centrales: la del crecimiento sin acumulación. Tal hecho está, además, vinculado a un proceso ampliamente generalizado: el escaso crecimiento que se da en el conjunto del Sistema Mundial capitalista se efectúa sin reparto en la absoluta mayoría de sus formaciones sociales (descartada en ellas la opción reformista).

Esto se correlaciona lógicamente con el hecho de que la hegemonía de la clase capitalista vaya quedando reducida a mera dominación (correlativa a una amplia desafección en crecientes capas de la población mundial) ${ }^{22}$. Se retroalimentan con ello las medidas de represión directa, desarticulación de la ciudadanía y destrucción de los elementos de seguridad social que fueron erigidos en "derechos" al nivel estatal. Tales medidas proliferan por doquier como manera de gestionar o regular un sistema a través de la crisis. Una "crisis" que, entonces, puede tender a cronificarse (como ya advirtiera Paul Mattick, 2009), y que en la hipótesis de algunos autores

${ }^{21}$ He mostrado en otros lugares (Piqueras, 2014a y 2014b) cómo en este momento histórico el capitalismo incumple crecientemente los dos principales elementos que constituyen su razón de ser: la conversión del dinero en capital (no otra cosa es la financiarización económica) y la conversión de seres humanos en fuerza de trabajo asalarizada (debido al proceso de mecanización y de incorporación de alta tecnología sobre todo, pero no sólo, en las formaciones de capitalismo avanzado).

${ }^{22}$ Las desigualdades sociales son tanto más toleradas cuanto que se compaginan con hechos favorables al común. Así, el crecimiento para todos. Cuando ello no se produce, la acaparación de las élites se hace más parasitaria y tiende también a contemplarse como más inútil y por tanto "injusta”. Es decir, menos tolerable.

Si se generalizan hechos como el que las tasas de rendimiento del capital sean 4 a 5 veces más elevadas que la retribución del trabajo, disparándose aquéllas cuanto más ocioso o especulativo es el capital, se está rompiendo también con todo el entramado justificativolegitimador del capitalismo productivo, que amparaba la desigualdad en el mérito, en el "hacer más útil”. 
apunta a la posibilidad de que hayamos entrado en un periodo de alta inestabilidad sistémica e incertidumbre propio de un capitalismo que no encuentra una nueva vía excepcional de acumulación para la que según algunos analistas es su "normal" situación de estagnación (especialmente vinculada esta última al triplete de monopolización-financiarización-globalización -Bellamy Foster y McChesney, 2012-) ${ }^{23}$. Un capitalismo, por tanto, posiblemente asentado en una indefinida "prolongación del estado estacionario" (Balakrishnam, 2009), muy probablemente forzado al "decrecimiento".

En estas circunstancias emprender un nuevo modelo de crecimiento con acumulación, o que la inacabada descomposición del keynesianismo (que ha tenido su primera parte en el neoliberalismo-financiarizado) se resuelva por fin en esa dirección, no se antoja tarea fácil. En lo inmediato las posibilidades pasan por cómo se decanten algunos procesos que se vislumbran decisivos.

Así, la creciente importancia del Bloque emergente parece estar desatando al menos unas fuerzas que chocan con las dinámicas señaladas en las formaciones centrales, cuando no apuntan directamente a las posibilidades de configuración de un nuevo modelo de crecimiento en el que se combine la planificación estatal con el papel del mercado como incentivador de la producción. Lo que tendencialmente dejaría atrás la hegemonía del neoliberalismo-financiarizado decadente.

Pero si el crecimiento subordinado de las economías emergentes permanece, podrían, en cambio, hacerse extensibles al conjunto del planeta las características del actual capitalismo periférico, profundizándose las tendencias ya existentes. De hacerse extensible el atolladero de acumulación al conjunto del sistema, y ante el agotamiento de reservas energéticas y primarias vitales, puede terminar por decantarse la guerra como elemento de "regulación" capitalista a escala internacional, proceso del que ya existen señales evidentes.

${ }^{23}$ Bellamy Foster y McChesney retoman los argumentos de Baran y Sweezy (1973), en cuanto a que la monopolización conlleva la profundización de la tendencia a la estagnación. Según estos autores, la drástica reducción de la competencia por el precio (el precio monopólico es el que marca la industria más grande), es sustituida por la acentuación de la competencia por la explotación de la fuerza de trabajo así como por la cuota de mercado a través de todo tipo de técnicas de ventas y publicidad. También se radicaliza la carrera por la ventaja tecnológica. Esto conduce más fácilmente a la estagnación, por las razones ya vistas en este trabajo. Por su parte, la pugna por una "low-cost position" a costa del capital variable lleva también al subconsumo, a cuenta de la mayor pauperización relativa de la fuerza de trabajo.

La acción combinada o "co-respectiva” entre monopolios en cuestión de precios, outputs e inversiones da como resultado una economía "demasiado productiva”, esto es, tendencialmente más proclive a la sobreacumulación. Para evitarlo, las grandes firmas monopólicas aceleran la globalización económica en su afán de derivar la inversión hacia lugares más alejados de la sobreacumulación. 
En cambio, si el capitalismo encontrase una nueva vía de acumulación, sus intrínsecas dinámicas del valor (obsolescencia programada, extractivismo energético, saturación de sumideros, producción altamente energívora...) conducirían probablemente a un "shock ecológico" (tengamos en cuenta que de seguir esta progresión, el PIB mundial se habrá multiplicado por 3 o 4 hacia 2050).

En el corto plazo el tipo de capitalismo que pudiera salir de la actual coyuntura dependerá por tanto de cómo se resuelvan las nuevas tensiones centros-periferias, especialmente en la producción de mercancías materiales (imprescindibles para que pueda existir un "capitalismo inmaterial” o cognitivo), y bajo qué división internacional del trabajo. Dependerá también de las posibilidades de desarrollar una alta eficiencia energética o de congeniar estructura económica e infraestructura ecológica (flujo de materiales y energía posibles en función del tamaño de la población, recursos disponibles, capacidades de los sumideros planetarios y consecuencias climáticas y ecológicas en general del modelo de crecimiento). Esto hace de vital importancia el factor demográfico, y en concreto cómo se enfrentará el crecimiento poblacional que se prevé deparará no menos de nueve mil quinientos millones de personas para 2050. Así mismo, cómo se gestionará la preservación y potenciación de las fuentes básicas de la reproducción de la vida, en cuanto a hábitats y recursos, pero también en lo que respecta a la seguridad social de las poblaciones.

Ninguno de esos problemas parece poder ser resuelto razonablemente sin algún tipo de planificación mundial, generalizada coordinación y colaboración de los seres humanos. Necesidades todas susceptibles de poner radicalmente en cuestión el conjunto de presupuestos que sustentan el modo de producción capitalista más allá de sus posibles modelos de crecimiento (individualismo, competencia a ultranza, maximización del beneficio propio, desigualdad social e internacional, consumo predatorio...). En el medio plazo pueden resultar asimismo altamente incompatibles con un sistema que requiere del crecimiento sin fin (permanente reproducción ampliada del capital y acrecentamiento de la masa de ganancia).

A todo ello nos falta añadir el ineludible factor subjetivo o factor humano. Es decir, cómo se va a manifestar el antagonismo de clase en función de una previsible generalización de la desafección social.

No por ser la última razón expuesta es la más baladí, pues la incapacidad de integrar a la dinámica de acumulación las "externalidades" decisivas, como las relacionadas con las luchas de clase, bien puede ser patente indicador del declive mórbido o degeneración de un sistema social que no da muestras de acabar de reconstituirse de su Segunda Larga Crisis y que se complica a sí mismo más cuanto más se aleja de su (parcial) versión reformista o distributiva.

\section{Bibliografía}

Aglietta, M. (1982) [1976]: Regulación y crisis del capitalismo, Madrid, Siglo XXI. Alonso, L.E. (1999): Trabajo y ciudadanía. Estudios sobre la crisis de la sociedad salarial, Madrid, Trotta. 
Alonso, L. E. (2007): La crisis de la ciudadanía laboral, Barcelona, Anthropos.

Alonso, L.E. y C. Fernández Rodríguez (2014). "Sacrificios para aplacar a los mercados: violencia y dominación en la crisis”, Documentación Social, 169.

Anisi, D. (1995): Creadores de escasez. Del bienestar al miedo, Alianza, Madrid.

Arrighi, G. (1999): El largo siglo XX, Madrid, Akal.

Balakrishnam, G. (2009): "Speculations on the Stationary State”, New Left Review, 59, pp. 5-26.

Baran, P. y P. Sweezy (1973) [1966]: El Capital monopolista: ensayo sobre el orden económico y social de Estados Unidos, México, D.F., Siglo XXI.

Bauman, Z. (2005): Vidas desperdiciadas, Paidós, Barcelona.

Bauwens, Michael (2005): “The Political Economy of Peer Production”. Disponible en web: http://www.ctheory.net/articles.aspx?id=499

Bellamy Foster, J. y R. W. McChesney (2012): "The Endless Crisis. How Monopoly-Finance Capital Produces Stagnation and Upheaval from the USA to China", The Monthly Review Press.

Bilbao, A. (1995): Obreros y ciudadanos. La desestructuración de la clase obrera, Madrid, Trotta.

Bilbao, A. (2000): "Modelo laboral, organización de las relaciones laborales y consenso", en VV.AA., Precariedad laboral, flexibilidad y desregulación, Alzira, Germania.

Boltanski, L. y È. Chiapello (2002): El nuevo espíritu del capitalismo, Madrid, Akal. Bond, P. y S. Khadija (2013): "Dosier sobre la cumbre de los BRICS". Disponible en web: http://www.sinpermiso.info/articulos/ficheros/bond.pdf

Boyer, R. (1992) [1987]: La teoría de la regulación. Un análisis crítico, Valencia, Edicions Alfons El Magnànim-IVEI.

Boyer, R. e Y. Saillard (2002) [1995]: Regulation Theory. The State of Art, Londres-Nueva York, Routledge.

Brenner, R. (1988): La economía de la turbulencia global, Madrid, Akal.

Carcanholo, R. (2009): "Capital ficticio y ganancias ficticias. Dos visiones críticas sobre el futuro del capitalismo", en Observatorio Internacional de la Crisis, $L a$ Gran Depresión del Siglo XXI: causas, carácter, perspectivas, San José, DEI.

Carcanholo, R. (2011): "Interpretaciones sobre el capitalismo actual, crisis económica y gastos militares” y Apéndice I: "Los gastos militares y la transustanciación de la riqueza”, en A. Piqueras y W. Dierckxsens (eds.), El colapso de la globalización. La humanidad frente a la gran transición, Barcelona, El Viejo Topo.

Carcanholo, R. y P. Nakatani (2000): "Capital especulativo parasitario versus capital financiero”, en J. Arriola y D. Guerrero (eds.), La nueva economía política de la globalización, Bilbao, Universidad del País Vasco.

Castel, R. (1997): La metamorfosis de la cuestión social. Una crónica del salariado, Barcelona, Paidós.

Chesnais, F. (2008): "El fin de un ciclo. Alcance y rumbo de la crisis financiera”, Herramienta, 37, Buenos Aires.

Chun, L. (2006): La transformación del socialismo chino, Barcelona, El Viejo Topo. 
Das, S. (2013): “El regreso de la crisis de los mercados emergentes”. Disponible en web: http://www.sinpermiso.info/textos/index.php?id=6352

Dekle, R. (1994): “Technological progress and endogenous capital depreciation: evidence from the US and Japan". Disponible en web: http://www.federalreserve.gov/pubs/ifdp/1994/485/ifdp485.pdf

Dierckxsens, W. (2012). "Horizontes de otra racionalidad económica / Crisis de legitimidad de una civilización". Disponible en web: http://www.observatoriodelacrisis.org/2012/03/horizontes-de-otra-racionalidadeconomica-crisis-de-legitimidad-de-una-civilizacion/ Observatorio internacional de la Crisis.

Dierckxsens, W. y A. Jarquín [Observatorio Internacional de la Crisis] (2012): Crisis y sobrevivencia. Ante guerreros y banqueros, San José, DEI.

Duménil, G. y D. Lévy (2006) : "La finance capitaliste: rapports de production et rapports de classe », en S. de Brunhoff, F. Chesnais, G. Duménil, M. Husson y D. Lévy, La finance capitaliste, Actuel Marx Confrontation, París, PUF.

Fumagalli, A. (2010): Bioeconomía y capitalismo cognitivo, Madrid, Traficantes de Sueños.

Fumagalli, A, S. Lucarelli, Ch. Marazzi, A. Negri y C. Vercellone (2009): La gran crisis de la economía global. Mercados financieros, luchas sociales y nuevos escenarios políticos, Madrid, Traficantes de Sueños.

Grossmann, H. (1979) [1929]: La ley de la acumulación y del derrumbe del sistema capitalista, Madrid, Siglo XXI.

Harvey, D. (2007): El nuevo imperialismo, Madrid, Akal.

Herrera, R. (2014): "Some Problems (and Paradoxes) Related to the Internationalization of China's Economy”, en R. Herrera, W. Dierckxsens y P. Nakatani. Beyond the Systemic Crisis and Capital-Led Chaos. Theoretical and Applied Studies, New York - Oxford, Peter Lang.

Hornstein, A. y P. Krusell (1996): "Can technology Improvements Cause the Productivity Slowdown?”, NBER Macroeconomics Annual, pp. 209-275. Disponible en web: http://www.nber.org/chapters/c11030

Jisi, W. y K. Lieberthal (2012): "Addresing US-China Strategic Distrust”. Disponible en web: https://www.brookings.edu/research/papers2012/03/30-uschina-lieberthal

López, I. y E. Rodríguez (2010): Financiarización, territorio y sociedad de propietarios en la onda larga del capitalismo hispano (1959-2010), Madrid, Traficantes de Sueños.

Loong Yu, A. (2009-2010): "China ¿Final de un modelo o nacimiento de un nuevo modelo?”, Revista Trasversales, 17. Disponible en web: http://www.nodo50.org/trasversales/

Lucarelli, S. (2009): "La financiarización como forma de biopoder “, en A. Fumagalli; S. Lucarelli, Ch. Marazzi, A. Negri y C. Vercellone (2009). La gran crisis de la economía global. Mercados financieros, luchas sociales y nuevos escenarios políticos, Madrid, Traficantes de Sueños. 
Marazzi, Ch. (2009): "La violencia del capitalismo financiero”, en A. Fumagalli, S. Lucarelli, Ch. Marazzi, A. Negri y C. Vercellone. La gran crisis de la economía global. Mercados financieros, luchas sociales y nuevos escenarios políticos, Madrid, Traficantes de Sueños.

Marques, R.M. y P. Nakatani (2009): O que é capital fictício e sua crise, Sao Paulo, Editora Brasiliense.

Mattick, P. (2009) [1934]: “The Permanent Crisis. Henryk Grossman’s Interpretation of Marx's Theory Of Capitalist Accumulation”, en The Council Communist Archive. Disponible en web: http://web.archive.org/web/20090221055640/ www.kurasje.org.

Mercatante, E. (2013): "China (problemas más hondos que algunas dificultades crediticias)”, en Punto de Desequilibrio. Crítica de la economía política. Disponible en web: http://puntoddesequilibrio.blogspot.com.ar/2013/06/chinaproblemas-mas-hondos-que-algunas.html

Midnight Notes Collective (2009): "Promissory Notes. From Crisis to Commons". Disponible en web: http://www.midnightnotes.org/Promissory\%20Notes.pdf

Naredo, J. M. (2006): Raíces económicas del deterioro ecológico y social, Siglo XXI, Madrid.

OIT [Organización Internacional del Trabajo] (2012): “Tendencias mundiales del empleo 2012. Prevenir una crisis mayor del empleo". Disponible en web: http://www.ilo.org/public/spanish/region/eurpro/madrid/download/tendenciasmu ndiales2012.pdf

Oxfam (2014): "Gobernar para las élites. Secuestro democrático y desigualdad económica”. Disponible en http://www.oxfamintermon.org/sites/default/files/ documentos/files/bp-workingfor-few-political-capture-economic-inequality-200114-es.pdf

Piketti, T. (2013) : Le capital au XXIe siècle, París, Seuil.

Piqueras, A. (2011a) : "De las crisis del capital al capital en crisis. Agotamiento de las posibilidades de reformismo en el capitalismo tardío", Actuel Marx. Intervenciones, 10, pp. 151-175.

Piqueras, A. (2011b): "Significado de las migraciones internacionales de fuerza de trabajo en el capitalismo histórico", en Andrés Piqueras y Wim Dierckxsens (eds.), El colapso de la globalización. La humanidad frente a la gran transición, Barcelona, El Viejo Topo.

Piqueras, A. (2014a): La opción reformista: entre el despotismo y la revolución. Una explicación del capitalismo histórico a través de las luchas de clase, Barcelona, Anthropos.

Piqueras, A. (2014b): "Notes on Class Struggle in Late Capitalism”, en R. Herrera, W. Dierckxsens y P. Nakatani. Beyond the Systemic Crisis and Capital-Led Chaos. Theoretical and Applied Studies, New York - Oxford Peter Lang.

Ríos, X. (2007): Mercado y control político en China: la transición hacia un nuevo sistema, Madrid, La Catarata.

Rodríguez, E. (2013): Hipótesis Democracia. Quince tesis para la revolución anunciada, Madrid, Traficantes de Sueños. 
Vercellone, C. (2004): "Las políticas de desarrollo en tiempos del capitalismo cognitivo", en A. Corsani, M. Lazzarato e Y. Moulier-Boutang, Capitalismo cognitivo, propiedad intelectual y creación colectiva, Madrid, Traficantes de Sueños.

Vercellone, C. (2010) : "La loi de la valeur dans le passage du capitalisme industriel au capitalisme cognitif”, European Journal of Economic and Social Systems, 23 (2), pp. 75-88. Disponible en web : http://ejess.revuesonline.com/ article.jsp?articleId=17019 [versión traducida en https://n-1.cc/blog/view/ 1537077/la-ley-del-valor-en-el-paso-del-capitalismo-industrial-al-nuevocapitalismo]

Vercellone, C. (2011): Capitalismo cognitivo, renta, saber y valor en la época posfordista, Buenos Aires, Prometeo.

Žižek, S. (2013). El año que soñamos peligrosamente, Madrid, Akal. 